\title{
Infrastructure Joint Venture Projects in Malaysia: A Preliminary Study
}

\author{
Norsyakilah Romeli $^{1 *}$, Faridah Muhamad Halil ${ }^{1}$, Faridah Ismail ${ }^{1}$, and Muhammad Sufian \\ Hasim $^{1}$ \\ ${ }^{1}$ Faculty of Architecture, Planning and Surveying, Universiti Teknologi Mara, Shah Alam, Malaysia
}

\begin{abstract}
As many developed country practise, the function of the infrastructure is to connect the each region of Malaysia holistically and infrastructure is an investment network projects such as transportation water and sewerage, power, communication and irrigations system. Hence, a billions allocations of government income reserved for the sake of the infrastructure development. Towards a successful infrastructure development, a joint venture approach has been promotes by 2016 in one of the government thrust in Construction Industry Transformation Plan which encourage the internationalisation among contractors. However, there is depletion in information on the actual practise of the infrastructure joint venture projects in Malaysia. Therefore, this study attempt to explore the real application of the joint venture in Malaysian infrastructure projects. Using the questionnaire survey, a set of survey question distributed to the targeted respondents. The survey contained three section which the sections are respondent details, organizations background and project capital in infrastructure joint venture project. The results recorded and analyse using SPSS software. The contractors stated that they have implemented the joint venture practice with mostly the client with the usual construction period of the infrastructure project are more than 5 years. Other than that, the study indicates that there are problems in the joint venture project in the perspective of the project capital and the railway infrastructure should be given a highlights in future study due to its high significant in term of cost and technical issues.
\end{abstract}

\section{Introduction}

The circumstance of the construction joint venture has been a standout amongst the most basic issues in the industry development. Many finished ventures were accounted for costs considerably higher than the genuine contract whole because of low quality. In Malaysia, the development part contributes altogether to the financial development for enhancing the personal satisfaction $[1,2,4]$. The development area has been assuming a critical part in total economy of the nation in term of its commitment to income era which energizes the total national output and the financial improvement of Malaysia. The construction industry

\footnotetext{
* Corresponding author: kilaromeli@gmail.com
} 
in Malaysia unanimously dominated by four pioneer fields which are construction of industrial, residential, commercial and infrastructure. The research focused on the infrastructure development as the construction cost for the infrastructure development is quite large it lead to the economic significant in Malaysian economic transformation history. Fig. 1 shows the infrastructure division in construction industry. The railway, highway, seaports, bridges, airports and dam are the example of the types of the buildable infrastructure elements. The infrastructure implementation is usually via joint venture, partnership, privatisation, and outsourcing $[16,18]$. Through the JV, a imperative measures usually discussed in IJVP is a collaboration pattern, time frame, infrastructure types, procurement selection, benefits from the collaboration, sharing elements, and financial determination $[3,4,6,20,21]$.

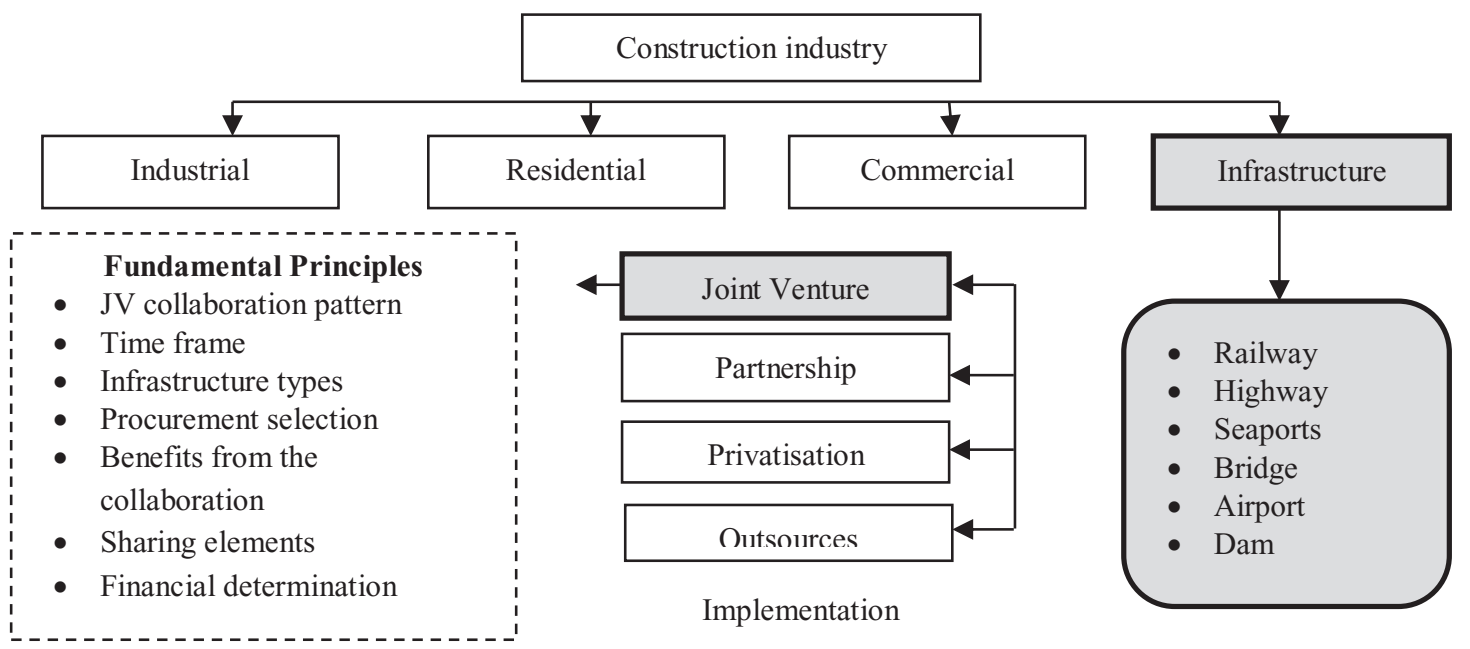

Fig. 1. The Infrastructure Division in Construction Industry.

\section{Landscape of Malaysian Infrastructure Joint Venture Projects}

The IJVP typically adhere with the involvement of private concessionaire in the delivery of public infrastructure worldwide is apparent in reducing the budgetary burden on the government's part specifically due to the major downturn in the global economy $[16,19]$. Their involvement varies from concessionaire, privatization to partnerships. [13,14,18]. Looking at the most current type of project delivery approach procured around the globe, which is known as Public Private Partnerships (PPP), although the opportunities are widely opened for the private concessionaires to partake in the delivery of public infrastructure projects with numerous incentives by the government, their responses are still minimal [911]. The clients appoint the Project Delivery Partners or Special Purpose Vehicle to manifest the project from the monetary acquisition, procurement path, tendering process and claim from the awarded contractors. A huge responsibility portray by the PDP to ensure the successfulness of the project $[17,19,20]$. Meanwhile, in certain project the IJVP occurred with the establishment of the new company for example ABJV to remarks the new legal organisation that will manifest the IJVP projects. The demand of the IJVP projects due to transferring the foreign technology to Malaysia for example the tunnelling process which requires expertise as in the application of New Austrian Tunnelling Method (NATM) and many others outstanding technologies in various infrastructure project [5-7]. Joint venture implementation is not new in Malaysia according to the current foreign direct 
investment to Malaysia which currently above the average levels at 67 per cent by year 2015 which indicated the sustainable implementation [12]; however there is relatively small exposure from the academic writing to uncover these matters [1,15]. Most of the knowledge gained from the Western reference via various research engines, however the research currently made at the Western countries and the legal and geographical factors may be different from the IJVP implementation in Malaysia.

Table 1. Research Trends on IJVP for past decades.

\begin{tabular}{|l|l|}
\hline \multicolumn{1}{|c|}{ Elements } & \multicolumn{1}{c|}{ List of Authors } \\
\hline $\begin{array}{l}\text { Involvement of the Public Sectors / } \\
\text { Privatisation/ Procurement Path }\end{array}$ & $\begin{array}{l}\text { Saleh \& Siong (2008), Oyegoke et al (2009), Molavi } \\
\text { \& Barral (2016), }\end{array}$ \\
\hline $\begin{array}{l}\text { Risk Sharing / Risk Discourse / Risk } \\
\text { Implementation / Risk Mitigation }\end{array}$ & $\begin{array}{l}\text { Annemiek et al (2015), Adnan et al (2008), Ravindhar } \\
\text { et al (2015), Zhang (2000), Thuyet et al (2004), } \\
\text { Larimo et al (2016) }\end{array}$ \\
\hline $\begin{array}{l}\text { Contractual Issues / Legal/ Dispute } \\
\text { Resolution / Conflicts }\end{array}$ & $\begin{array}{l}\text { Ismail et al (2012), Marani et al (2014), Carmichael et } \\
\text { al (2015), Welch et al (2000), }\end{array}$ \\
\hline $\begin{array}{l}\text { Key Performance Indicator / Critical } \\
\text { Success Factor / Technology Transfer / } \\
\text { Knowledge Management }\end{array}$ & $\begin{array}{l}\text { AS Bakri et al (2009), SS Khaderi et al (2009), } \\
\text { Famakin et al (2012), Masrom et al (2015), Ozorhon } \\
(2014), \text { Takim \& Akintoye (2008), AbdulAziz et al } \\
\text { (2009), Ondo (2012), Ling et al (2012) }\end{array}$ \\
\hline $\begin{array}{l}\text { Urban Growth / Development / } \\
\text { Implementation }\end{array}$ & $\begin{array}{l}\text { Ma \& Voo (2011), Famakin et al (2012), Charlebois } \\
\text { (2008) }\end{array}$ \\
\hline $\begin{array}{l}\text { Behaviour / Organisational Management/ } \\
\text { Human resources formation }\end{array}$ & $\begin{array}{l}\text { Savrina \& Rimsa (2013), Cheung (2009), Shaoul et al } \\
\text { (2013), Henry (2010) }\end{array}$ \\
\hline $\begin{array}{l}\text { Project Capital/ Financing / Investment/ } \\
\text { Economical Challenges }\end{array}$ & $\begin{array}{l}\text { Flyvbjerg et al (2004), Khang \& Thao (2015), Howes } \\
\text { \& Robinson (2005), Merna \& Njiru ( 2002), Romeli et } \\
\text { al (2016), Dziadosz (2015), Bakar et al (2012), } \\
\text { Wonglimpiyarat (2016), Hwang et al (2003) }\end{array}$ \\
\hline
\end{tabular}

Other than that, there is depletion in information on the actual practise of the infrastructure joint venture projects in Malaysia. The depletion can be seen through the research trend analysis for past decades at Table 1 . The issues on the project capital and financing been explored by majority of the foreign researcher and only few from the local. Less highlights given to the IVP in Malaysia on financial matters compares to risk, key performance indicator, critical success factors and knowledge management. Therefore, the circumstances suited the purpose of this study which attempt to explore the real application of the joint venture in Malaysian infrastructure projects.

\section{Methodology}

The methodology used in this research is quantitative methods. Therefore an instruments used is questionnaire survey. The respondent sample is selected based on the purposive sample. The list of contractors derived from the Construction Industry Development Board (CIDB), later on 35 numbers of infrastructure contractors selected according to the higher class in the contractor's registration with years of the establishment of the organisation more than 30 years. The purpose of selection is due to the higher years of the company establishment represent the validity of the response based on their experience in the infrastructure development. The questionnaire survey are divided into three (3) sections as Section A is for The Respondent Details, Section B is for Overview of the IJVP and Section $\mathrm{C}$ is for The Project Capital in Infrastructure Joint Venture Project. In within 6 months, the response recorded and keyed in the Statistical Package for Social Science 
(SPSS) software and then analysed via the frequency analysis. The findings of the research documented as chapters below.

\section{Results and discussions}

\subsection{Section A: The Respondent Details}

The outcome of this section can be view at the Fig. 1 to 6 below. For the professional background, there are 40 per cent of the respondents are quantity surveyors, followed by 27 per cent engineer, 23 per cent project manager and 10 per cent is architect. As for the working experience there are 34 per cent of them with 10 to 15 years of working experience, 33 per cent at 5 to 10 years and 23 per cent less than 5 years. The results show that the respondents are among the professional practitioner that valid to answer the questions. Therefore the results shows that findings of this research from the reliable sources. The questions also asked about the preferable sharing ration in their company. The results indicated that 46 per cent of them agreed the JV sharing ration is 50\%:50\%, followed by 27 per cent respectively for ratio of 30\%: 70\% and 60\%:40\%. The respondents also had more experience implemented JV with local partner at 66.67 per cent rather than foreign partner at 63.33 per cent. Meanwhile, the respondent collaboration partner's countries are highest with the Asian partners at 96.67 per cent, followed by Middle East at 33.33 per cent, European at 25.42 per cent, and Oceania at 8.47 per cent, and America at 0.00 per cent and Africa at 0.00 per cent. This shows that the JV can be a continent approach for the Asian countries as the collaboration term and geographical factor slightly acceptable rather than other continents in the world. For types of JV partners the respondents agreed that the preferable JV approach implemented is among the client or owner at 76.67 per cent, followed by supplier at 70.00 per cent, manufacturer at 70.00 per cent, sub contractors at 63.33 per cent, specialist at 56.67 per cent and consultant at 16.67 per cent. The results indicated that the flows of the joint venture may smooth and practical with the collaboration partners of owner and clients compared to consultants. It is understood that from the Section A that the characteristics of the IJVP practitioners are identified and can be the guideline to the future researcher to acknowledge the respondents in this study area.

\subsection{Section B: The Overview of the Infrastructure Joint Venture Projects}

The questionnaire gets into the deeper essence of the knowledge where the enquiries on overview of the infrastructure joint venture project asked in the survey sessions. The questions are comprises of the types of JV implemented, the typical IJVP construction period, the IJVP construction cost, the classification of the IJVP, the IJVP procurement selection, benefits from the collaborations and the sharing IJVP elements. The outcome of the research is presented at the Figure 7 to 13 below. The results indicated the typical types of JV implemented are incorporated joint venture at 83.33 per cent compared to unincorporated joint venture at 63.33 per cent. The number shows that the respondents prefer to implement the JV via establishing a new company rather than appointing the project delivery partner as parts of the JV structure. 


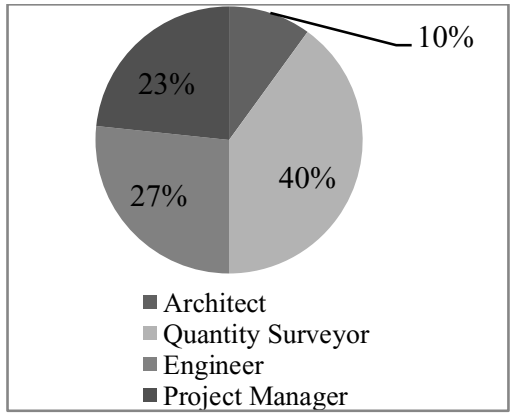

Fig.2.Professional Background.

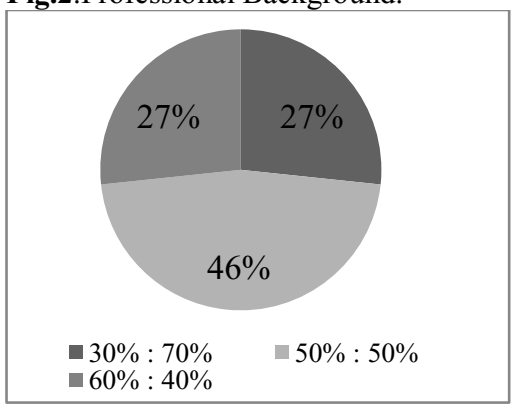

Fig.4.JV Sharing Ratio.

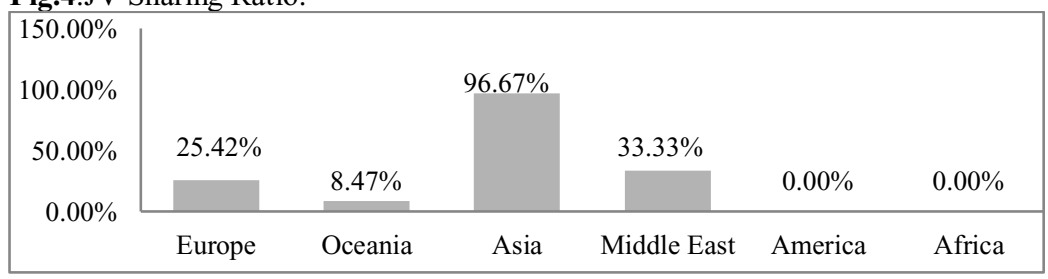

Fig.5. Collaboration Partner Range.

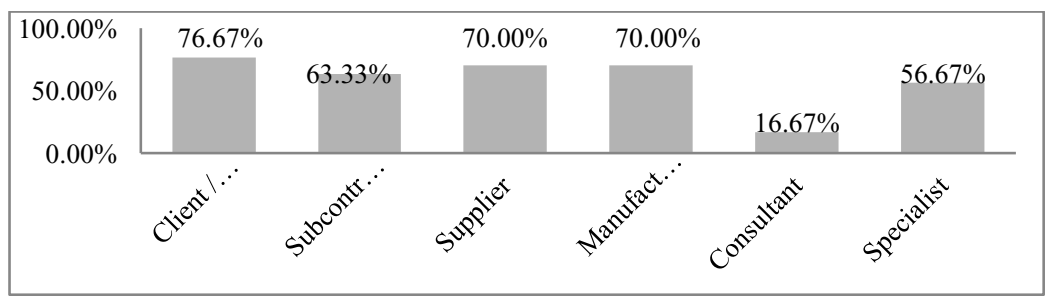

Fig.6. Types of JV Partners.

For the IJVP period of construction the 63.33 per cent answer recorded on more than 5 years, followed by 33.33 per cent for 3 to 5 years, 26.67 per cent for one to 3 years, and 0.00 per cent for less than a year. The results indicated that the IJVP construction period took longer than normal construction period due to the complexities of the projects. For the IJVP construction cost, the highest poll is on the MYR 50 Billion to MYR 100 Billion at 66.67 per cent, followed by 33.33 per cent for MYR 10 Billion to MYR 50 Billion, 26.67 per cent for below MYR 10 Billion and 13.33 per cent for more than MYR 100 Billion. The results shows that the IJVP required a big financial fund due to the big infrastructure development, material, manpower as well as the new technology adopted making the project required large financial resources. For the classification of the IJVP, the respondent agreed that the IJVP usually held for the highway project at 66.67 per cent, followed by 
bridges at 33.33 per cent, dam, airport and seaports at 16.67 per cent and railway at 13.33 per cent. The results show that the IJVP commonly focus on the highway infrastructure rather than railway infrastructure. Therefore, the concentration towards railroad infrastructure been given fewer highlights in Malaysian joint venture framework. For the procurement path, the respondent agreed Design and Build has been the typical procurement path available for the IJVP at 83.33 per cent, followed by Engineering, Procurement and Management Contract at 33.33 per cent, Traditional Method at 16.67 per cent, Turnkey at 10.00 per cent, and Emerging Cost Contract at 6.67 per cent. The results shows that the IJVP practitioner perceived infrastructure construction via the Design and Build approach are likely more doable rather than Emerging Cost Contract.

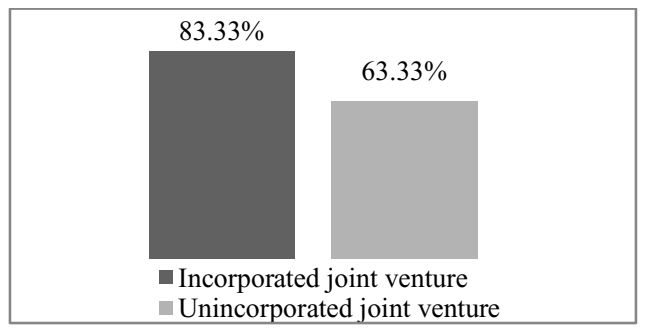

Fig.7.Types of JV.

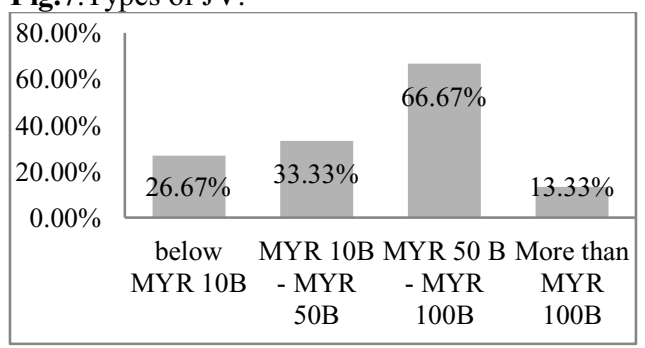

Fig.9.IJVP cost.

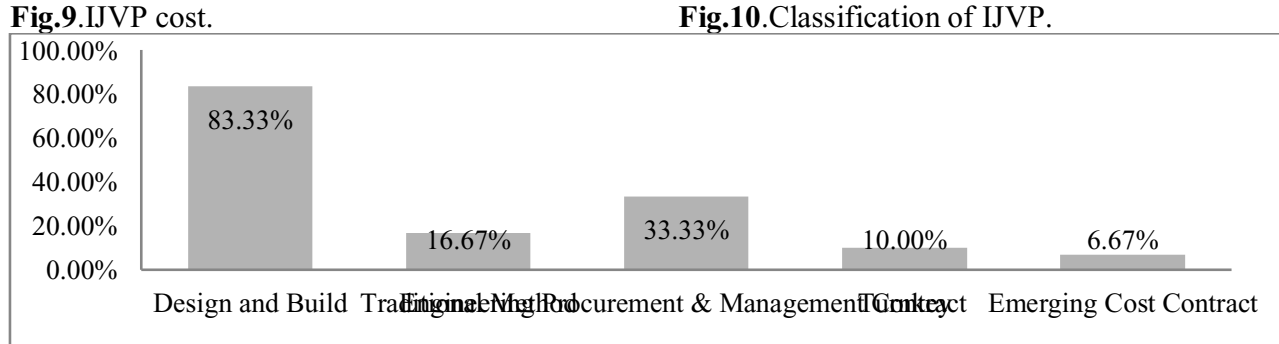

Fig.11. IJVP Procurement Path.

For the perspective of the benefits of the collaboration the respondent agreed that the implementation of the IJVP are based on the legal reason which the highest score is at 83.33 per cent, followed by sharing benefits at 70.00 per cent, minimizing cost at 63.33 per cent, employment at 56.67 per cent, strategic goals and purpose of survive at 46.67 per cent respectively. The results show that most of the establishment of IJVP in Malaysia are based on the legal procedure in the country itself. This has supported by the implementation of the Construction Industry Transformation Program which allow the joint venture implementation in Malaysia establish from 35 percent of the non - Malaysian in any joint venture infrastructure development in Malaysia. Apart from the benefits of the collaboration, the outcome on the preferable sharing elements is derived from this research. There are 93.33 per cent response recorded on risk, followed by market at 83.33 per cent, 
tax at 80.00 per cent, property at 76.67 per cent, manpower at 73.33 per cent, services for 66.67 per cent, technology and monetary at 40.00 per cent respectively, managerial style at 33.33 per cent, and culture at 30.00 per cent. The results indicated that the preferable elements to be share among the IJVP practitioner are risk as they perceive the risk is imperative rather than the culture. This is aligning with the research by local author Adnan (2008) on her research in construction risk implementation management in IJVP Malaysia. The research focused on the perception of the contractors in Malaysia that concern the contractors the most on the risk implementation process. The researches however generally discuss risk, and in depth study are required to explore the risk stated by the author especially on the technical and financial risks. Hence, the issues on the IJVP financial then explored at the Section C.

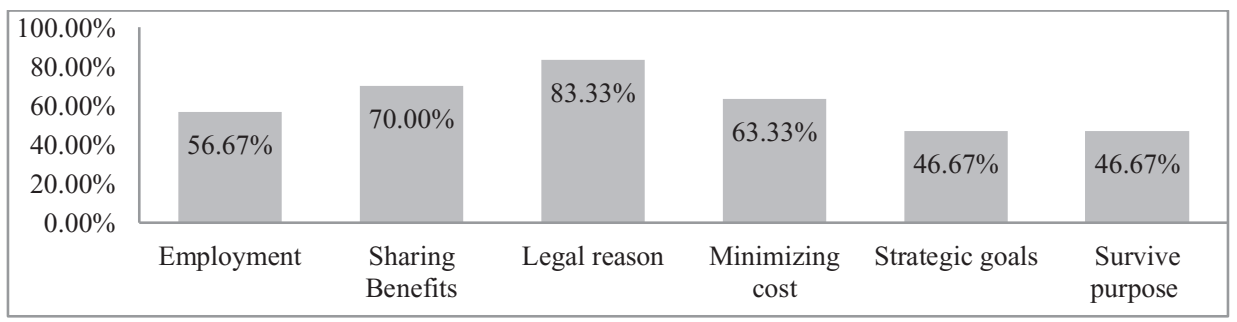

Fig.12.Benefits from the collaboration.

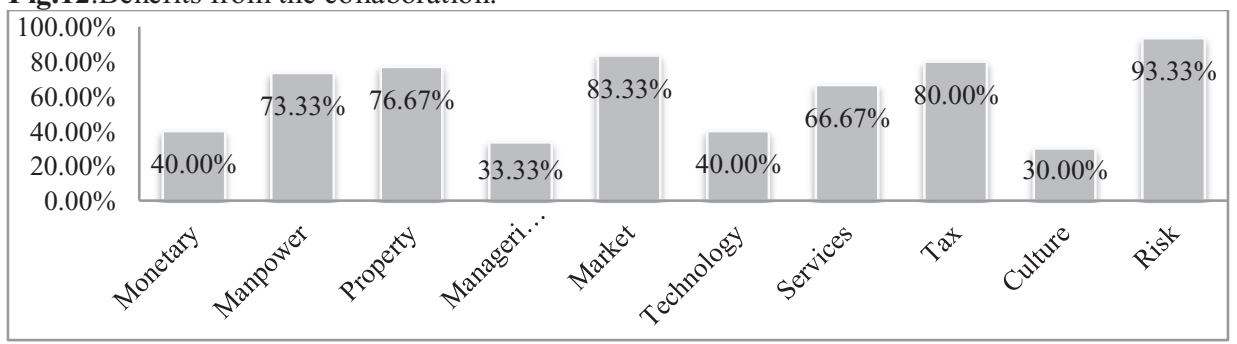

Fig.13.The JV sharing elements.

\subsection{Section C: The Project Capital in Infrastructure Joint Venture Project}

The outcome from this section explored on the financial side of the IJVP. The financial issues that mostly top of the practitioner's worries are the project capital as it is the start up instrument to commence the project. Hence, the question on the barriers in project capital acquisition, benefits of comprehensible project capital acquisition and attributes to project capital improvement been asked. The results from the questionnaire survey are as follows.

\subsubsection{Barriers in Project Capital Acquisition}

Fig 14 shows that the respondent response on the barriers in project capital acquisition in the IJVP. The results shows that the highest response are on the lack of financial aid at 83.30 per cent, followed by hard to control the project capital at 70.00 per cent, less understanding on the project capital contractual term and condition at 33.33 per cent, and the project capital expenditure accuracy at 30.00 per cent. The results show that the resources of the project capital are lacking in the IJVP. Although the government provides huge funding aid to support the projects, it is still insufficient as the normal infrastructure project would cost around MYR 50 Billion to MYR 100 Billion. Other than that, the difficulties to control the project capital can lead to the damage of the project financial flows. There are the needs for the better control tools or instrument to manifest the flow of 
the project capital at the initial, recurring and completion of the project. It is advisable for the project practitioner to control their tools via Code of Accounts Structure, Definitive Cost Estimate, Engineering Labour Report, Field Labour Report, and Project Cost Summary. These tools are imperative to estimate the outflow and inflow of the project capital in IJVP. The understanding of the project capital term and condition must be interpret by the legal practitioner to avoid the breach of the contract, upon the project capital utilisation phase as if the project capital is in term of the bank loan, the practitioner are required to pay the loan in within payback period with certain interest rates. The failure to comply with the contract leads the IJVP practitioner into the financial fatality stage. The accuracy of the project capital expenditure are among the problems do jeopardise the performance of the project capital. Hence, the better project cost planning and framework are required to sustain the project capital expenditure in the future.

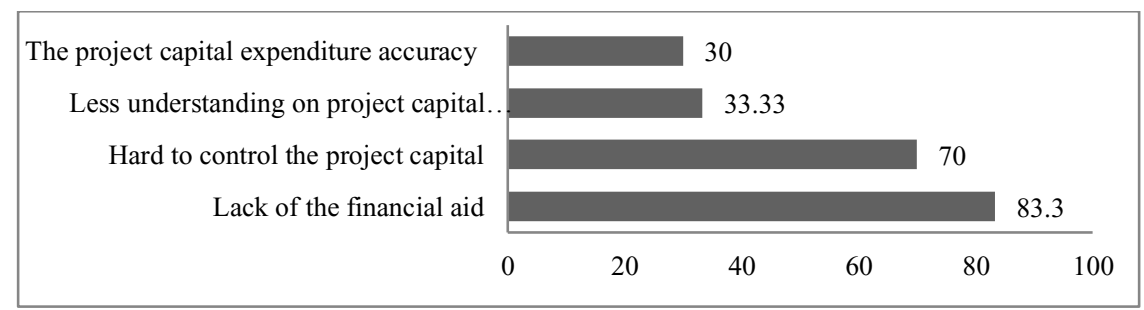

Fig.14.Barriers in Project Capital Acquisition.

\subsubsection{Benefits of Comprehensible Project Capital Acquisition}

Fig. 15 shows the results on the benefits of comprehensible project capital acquisition in IJVP. The results indicated that the benefits of the comprehensible project capital acquisition are as the structure for partner fit at 73.33 per cent, followed by financial stability at 66.67 per cent, to avoid dispute at 40.00 per cent and shows the mutual interest at 36.67 per cent. The respondents agreed that the structure fit are among the most benefits of having a comprehensible project capital acquisition as the foundation of having the IJVP is to share the monetary matters and distribute the risk accordingly and the measurement towards the successful joint venture project are having the project successfully fits. Meanwhile the project capital strength is act as the financial stability in ones project which the contingencies cost can be overcome if the organisation obtains the financial stability. Besides that, the dispute can be handling wisely with the existence of the stable project capital as the common dispute occurred due to the financial crisis in the organisation. The mutual interest in this research score the least as the respondent perceived that there is other matters in the IJVP can represent the mutual interest among the collaboration partners.

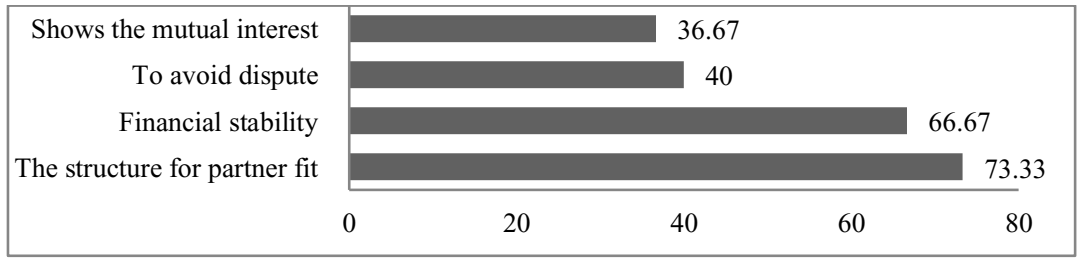

Fig.15. Benefits of Comprehensible Project Capital Acquisition. 


\subsubsection{Attributes to Project Capital Improvement}

Fig. 16 shows that the results on the attributes to project capital improvement in IJVP. The results indicated that the respondents agreed that the attributes are to have better tools to supervise the flow of the project capital at 74.00 per cent, followed by concentration on project capital contractual form at 67.00 per cent, adequate funding base at 40.00 per cent, and a good networking skills at 37.00 per cent, and better construction cost planning at 21.00 per cent. The results indicated that the tools to supervise the flow project capital are required in this industry of IJVP. Hence, the improvement of the project capital shall focus on the control tools. Besides that, the understandable contractual form is needed to improve the project capital performance and stability. Hence, the capital project can be improved with the deeper understanding of the practitioner while handling the IJVP projects. The characteristic of adequate funding base a likely preferably by the respondents too, as the availability of the project capital are lack of the source so the IJVP practitioner shall do networking, do target the investor and investigate the investors background to improve the project capital. Apart from that, the IJVP practitioners may need to do the background check on the investors due to the term and condition from the lenders may distinguish from another. Some of the IJVP may also do come up with the better construction cost planning and development proposal to attract multi - types of investor towards the successful funding of the IJVP. From the project capital acquisition process, the research found that there is so much the strategies are needed to improve the project capital as the stability of the project capital are uncertain, therefore there is an art to lever it.

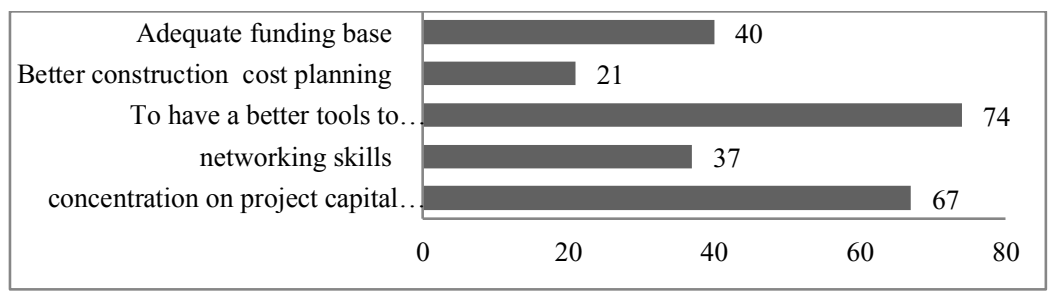

Fig.16. Attributes to Project Capital Improvement.

\section{Conclusions}

As the conclusion the IJVP implementation are mostly in between contractors and client with the usual construction period of the infrastructure project are more than 5 years with the project cost are high and the procurement path also complex due to the project needs. The collaboration made among the local practitioners and for the foreign IJVP the construction mostly among the Asian countries and the typical infrastructure development are highways instead of railways. The collaboration made based on the legal reason with the high level of risk sharing and mitigation awareness as the concern of the collaboration is on the monetary perspectives. Other than that, the study indicates that there are problems in the joint venture project in the perspective of the project capital and the railway infrastructure should be given a highlights in future study due to its high significant in term of cost and technical issues. Hence, the research provides an ample justification on the current practise of the infrastructure joint venture project in Malaysia. This research would deliver a general picture on the joint venture in infrastructure project in Malaysia to the body of knowledge and as well as the construction practitioner. 
The authors would like to thank all of the infrastructure contractors for the good feedback received as well as the best commitment given by them. Special thanks to the personnel from the UEM Berhad and $\mathrm{MMC}$ - Gamuda for the warmest treatment during the poll session.

\section{References}

1. Z.Abu Bakar. UTM. (2008)

2. Abdul-Aziz, A.-R., Lee, K. Z. Ltd Intl J of Enrgy Sect Mgmt 1 (2009)

3. Adnan, H. UiTM, 99-106. (2008)

4. Bakri, A. S., Ingirige, Amaratunga D. Salford Univ, UK. Schl of Blt Envrnmt. (2008)

5. Famakin, I. O., Aje, I. O., \& Ogunsemi, D. $J$ of Fncl Mgmt of Prprty \& Cons 17 (2012)

6. Howes, R., \& Robinson, H. Elsevier B.V. (2005)

7. Ismail, S., Md Yusof, A., Soon Han, W. IBIMA Bis Rev, 11 (2012)

8. M.A.Ravindhar Raja, M.Gayathri, Knight, G. M. S. Intl J of Civ Eng \&Tech 6 (2015)

9. Ma, T., \& Voo, M.. A 2014 EPPM Conf at Por Elizbth, ZA, (2014)

10. Marani, D. A. A., Danuri, M. S. M., \& Mohamed, O. Intl J of Prprty Sc 4 (2014).

11. Masrom, M. A. N., Rahim, M. H. I. A., Mohamed, S., Chen, G. K., \& Yunus, R. Procedia Eng 125 (2015)

12. MIDA, e-newsletter, 2 (2016)

13. Molavi, J., \& Barral, D. L. A. Procedia Eng 145 (2016).

14. Oyegoke, A., Dickinson, M., Khalfan, M., McDermott, P., \& Rowlinson, S. Intl J of Mg Prjct in Biz 2 (2009)

15. Romeli, N., Halil, F. M., Ismail, F., Abd Shukor, A. S. Procedia - Soc Behav Sci 234 (2016)

16. Salleh, D., \& Siong, H. C. J Alam Bina 11 (2008)

17. State, O. J Cons Prjct Mgmgt \& Innov 2 (2012)

18. Takim, R., Adnan, H. Asian Soc Sci 4 (2008)

19. Thuyet, N. Van, Ogunlana, S. O., Dey, P. K., Pongsiri, N. Intl J Public Sect Mgmt J of Biz 17 (2004)

20. Van Os, A., Van Berkel, F., De Gilder, D., Van Dyck, C., Groenewegen, P. Intl J of Prjct Mgmt 33 (2015)

21. Zhang, S. Kyoto Univ, (2000) 